\title{
Os significados que os alunos da EJA têm em relação à instituição escolar
}

\section{TCC article: adolescent and adult education students' meanings in relation to school as an institution}

Andressa Cardoso Gomes ${ }^{1}$

1 Aluna de graduação. Universidade do Estado da Bahia (UNEB), Brasil. E-mail: andreessagomes@hotmail.com

Recebido em: 07/10/2014 | Aprovado em: 21/05/2015

DOI: $10.12957 /$ interag.2015.13197

\section{Resumo}

O presente artigo analisa os significados que os alunos da modalidade de Educação de Jovens e Adultos atribuem à escola. O mesmo foi realizado a partir de um estudo de caso na Escola Municipal de Passagem Velha, localizada na Zona Rural da cidade de Senhor do Bonfim-BA. A pesquisa teve como finalidade principal compreender a importância que os alunos atribuem à escola e os fatores motivantes para frequentar a instituição. Para problematizar o trabalho contamos com aportes teóricos dos autores: Arroyo (2005), Costa (2001), Di Pierro (2005), Freire (1980,2000 e 2005), Gadotti (2001), Haddad (2000), Paiva (1987) entre outros que cooperaram na discussão da temática. A partir dos resultados alcançados, ambiciona-se expandir 0 debate sobre a importância da escola na vida dos alunos.

Palavras-chave: Educação de jovens e adultos; Significados; Escolarização; Escola do sujeito.

Área temática: Educação.

Linha de extensão: Alfabetização, leitura e escrita.

\begin{abstract}
This article focuses on the meanings that Adolescent and Adult Education students ascribe to school. A similar study was held based on a case study at the Municipal School of Passagem Velha, located in the rural city of Senhor do Bonfim, in Bahia. The main purpose of the research was to understand the importance that students attach to the school and the motivating factors for attending the institution. To discuss the work we have theoretical contributions of the following authors: Arroyo (2005), Costa (2001), Di Pierro (2005), Freire (1980, 2000 and 2005), Gadotti (2001), Haddad (2000), Paiva (1987) and others who cooperated in the discussion of the subject. From the results achieved, we aim to expand the debate on the importance of school in the students' lives.
\end{abstract}

Keywords: Adolescent and adult education; Meanings; Schooling; School of the subject.

\section{Introdução}

A Educação de Jovens e Adultos (EJA) tem representado um grande desafio para um projeto de educação universalizante no Brasil, uma vez que é destinada àqueles que não tiveram acesso à escola na idade própria, reveste-se de características específicas que a tornam uma tarefa difícil de ser consolidada.

No entanto, os avanços na oferta dessa modalidade de educação têm sido notados e o acesso dos alunos à escola vem ocorrendo de maneira gradativa e constante, num 
demonstrativo claro de que há um interesse pela escolarização que não foi alcançada na idade e tempo próprios.

A Educação de Jovens e Adultos tem início a partir de movimentos de lutas e desejos da educação popular e sempre foi vista como uma tarefa difícil, por atender uma camada da população carente que não teve acesso à escola em tempo desejado; por isso representa um momento de uma nova significação na vida para os que a ela têm acesso.

A partir dessa constatação surgiu o interesse em compreender os significados que os discentes desta modalidade de ensino têm da escola, tendo em vista que o acesso a ela demonstra ter um certo significado para a vida dos mesmos. Portanto, o presente trabalho de conclusão de curso discute o significado da escola para a vida dos alunos da EJA, procurando conhecer os motivos que os levam a frequentar a instituição.

Essa curiosidade foi despertada primeiramente pelo fato de convivermos com alunos frequentadores da EJA, conhecer suas histórias de vida, mas desconhecer esses significados. Outro ponto que contribuiu fortemente na escolha deste tema foi a colaboração em uma turma de EJA, em que essa experiência nos proporcionou uma identificação com a referida modalidade de ensino.

Assim, o presente trabalho se propôs a conhecer os significados que os alunos da EJA atribuem à instituição escolar; se a mesma atende as suas necessidades e se a educação oferecida contribui significativamente para uma melhoria na qualidade de vida desses discentes.

Esse trabalho teve como modelo de pesquisa o estudo de caso que foi realizado na Escola Municipal de Passagem Velha, em uma turma de EJA de ensino fundamental II, composta por 20 alunos matriculados e 3 docentes. A pesquisa realizada utilizou como instrumento observações em campo e entrevistas através da aplicação de questionários.

Para contribuir com a discussão sobre o tema em questão tivemos a colaboração de autores como: Arroyo (2005), Costa (2001), Di Pierro (2005), Freire (1980, 2000 e 2005), 
Gadotti (2001), Haddad (2000) e Paiva (1987) que forneceram subsídios significativos para a contextualização e compreensão da pesquisa.

\section{Educação de Jovens e Adultos (EJA): um breve histórico}

Para uma melhor compreensão da Educação de Jovens e Adultos (EJA), na atualidade, se faz necessário uma retrospectiva histórica, visto que entendendo o alicerce poderemos analisar os processos ideológicos do fazer Educação de Jovens e Adultos no Brasil.

A Educação de Jovens e Adultos no Brasil tem registro a partir da colonização, quando os jesuítas catequizavam os índios, em sua maioria adultos, com o método denominado RatioStudiorum que consistia em um plano de estudos transmitido pela oralidade. Com a expulsão dos jesuítas, só ouviremos falar de Educação de Jovens e Adultos no Império quando a constituição de 1824 garantia a "instrução primária e gratuita para todos os cidadãos”. O que sugere a inclusão, também, dos adultos.

Na Primeira República, as reformas educacionais foram realizadas em grande número e poucos resultados consideráveis, o que se traduz em $72 \%$ da população acima de cinco anos em estado de analfabetismo. A partir de 1930, foram percebidas condições desejáveis para a inserção de políticas públicas para a Educação de Jovens e Adultos, uma vez que tem início o processo de industrialização e de aceleração da urbanização no Brasil. Porém, somente no final da década de 1940 a Educação de Jovens e Adultos é reconhecida e tem um tratamento particular, devido ao recenseamento o qual indicava que 55\% da população com mais de 18 anos não havia sido alfabetizada. Foi criada então uma rede de ensino supletivo para adultos não alfabetizados na perspectiva de atender as carências existentes e tentar reduzir os altos índices registrados.

Ratificando a atenção dada a esta modalidade de educação, no ano de 1947 é criado o Serviço de Educação de Adultos que tinha como objetivo a supervisão geral dos trabalhos dos planos anuais do ensino supletivo para adolescentes e adultos analfabetos. Este órgão 
contribuiu incentivando a opinião pública, as esferas governamentais e as instituições privadas para uma política mais efetiva desta modalidade de ensino.

A partir de então, a Educação de Jovens e Adultos deixou de ser tratada como fragmento e passou a ser contemplada com políticas específicas, fato esse que se deu pelas pressões populares que buscavam melhores condições de vida, na visão de que a educação era elemento fundamental para que o Brasil se concretizasse como nação desenvolvida. Sobre isso Haddad e Pierro nos dizem que:

\footnotetext{
Os compromissos com a educação objetivavam a "formação de uma infra- estrutura adequada de recursos humanos, apropriada ás nossas necessidades socioeconômicas, políticas e culturais”. Para a implantação de tais objetivos, o Estado brasileiro se propunha a criar e programar um sistema de educação permanente, no qual a educação de adultos situa-se "na linha das operações", por ser "poderosa arma capaz de acelerar o desenvolvimento, o processo social e a expansão ocupacional". ${ }^{1}$
}

No período que se estende de 1959 a 1964 a Educação de Jovens e Adultos é assunto frequente através de diversos programas voltados a essa modalidade de ensino e passa a ser reconhecida como um forte instrumento de ação política, por possuir uma grande responsabilidade de resgate e reconhecimento do saber da massa popular.

Em 1964, tem início o Plano Nacional de Alfabetização com a implantação de programas de alfabetização idealizados por Paulo Freire em todo o território nacional, que tinha como alicerce uma nova compreensão da relação entre a problemática educacional e a problemática social, através de uma ação educativa que não relegasse a cultura do indivíduo. Para Freire:

\footnotetext{
Se antes a alfabetização de adultos era tratada e realizada de forma autoritária, centrada na compreensão mágica da palavra, palavra doada pelo educador aos analfabetos; se antes dos textos geralmente oferecidos como leitura aos alunos escondiam muito mais do que desvelavam a realidade, agora, pelo contrário, a alfabetização como ato de conhecimento, como ato criador e como ato político. ${ }^{2}$
} 
Assim, Freire desenha a Educação de Jovens e Adultos como uma ação que deve aproveitar os conhecimentos dos sujeitos envolvidos, bem como propiciar seu desenvolvimento tornando-os responsáveis pelo seu próprio aprendizado.

Com o golpe militar houve uma repressão na educação de adultos sendo os seus instrutores reprimidos e os idealizadores expulsos do país, inclusive Paulo Freire. Paiva nos diz que:

\footnotetext{
A multiplicação dos programas de alfabetização de adultos, secundada pela organização política das massas, aparecia como algo especialmente ameaçador aos grupos direitistas; já não parecia haver mais esperança de conquistar o novo eleitorado (...) a alfabetização e educação das massas adultas pelos programas promovidos a partir dos anos 60 aparecia como um perigo para a estabilidade do regime, para a preservação da ordem capitalista. Difundido novas idéias sociais, tais programas poderiam tornar o processo político incontrolável por parte dos tradicionais detentores do poder e a ampliação dos mesmos poderia até provocar uma reação popular importante a qualquer tentativa mais tardia de golpe das forças conservadoras. ${ }^{3}$
}

Desta forma, o governo só autorizou a ação de programas de alfabetização de adultos de maneira conservadora e assistencialista, a partir de 1967 quando o governo militar assume esses programas e dá início ao MOBRAL (Movimento Brasileiro de Alfabetização), que tinha por finalidade erradicar o analfabetismo e prover a educação continuada aos jovens e adultos. Para alunos egressos do programa é criado o ensino supletivo tendo em vista que a experiência com o MOBRAL demonstra a necessidade da ampliação da escolarização.

A política de educação aplicada pelo MOBRAL consistia em codificações de palavras preestabelecidas, muito semelhante ao método utilizado anteriormente por Paulo Freire. A diferença estava na utilização das palavras para todo o Brasil: enquanto o método de Paulo Freire respeitava as individualidades regionais, o MOBRAL ensinava a ler, escrever e contar; assim, relegava a autonomia e a capacidade crítica de cada indivíduo de forma descontextualizada tendo em vista que o material didático era comum para todas as regiões do país. Desta maneira, o MOBRAL foi um programa criado para 
atender as necessidades e interesses do governo militar que não utilizava o diálogo e não respeitava as singularidades existenciais.

Em 1985, o MOBRAL foi extinto devido à estigmatização como modelo de educação domesticadora e de baixa qualidade e é criado em seu lugar a Fundação Nacional para Educação de Jovens e Adultos (Fundação Educar) que funcionava com o apoio de organizações não governamentais e de instituições privadas. A partir de 1988, com a nova Constituição, o Estado amplia o dever com a educação de adultos, e determina a garantia de ensino fundamental obrigatório e gratuito, assegurando sua oferta para todos os que a ele não tiveram acesso na idade própria.

Nos anos 90, com uma situação em que $20 \%$ da população brasileira, com média de idade de 15 anos ou mais era analfabeta, é promulgada a nova Lei de Diretrizes e Bases da Educação Nacional no 9394/96 que em seu Art. 4 contempla a Educação de Jovens e Adultos assegurando a "oferta de educação escolar regular para jovens e adultos, com características e modalidades adequadas às suas necessidades e disponibilidades, garantindo aos que forem trabalhadores as condições de acesso e permanência na escola".

Já em 2000, é lançado o programa Brasil Alfabetizado que busca diminuir as taxas de analfabetismo. O programa é organizado em edições anuais, com os alfabetizadores contratados por meio do sistema de bolsas que não mantêm vínculos empregatícios. A meta do programa é traçada de acordo com o mapa do analfabetismo em cada região brasileira. Segundo o MEC:

O programa é uma porta de acesso à cidadania e o despertar do interesse pela elevação da escolaridade. O Brasil Alfabetizado é desenvolvido em todo o território nacional, com o atendimento prioritário a 1.928 municípios que apresentam taxa de analfabetismo igual ou superior a 25\%. Desse total, 90\% localizam-se na região Nordeste (MEC 2003). ${ }^{4}$

Em 2007, é lançado o Plano Nacional do Livro Didático para a Alfabetização de Jovens e Adultos, e, em seguida, essa modalidade de ensino é incorporada ao Fundo de 
Desenvolvimento da Educação Básica (FUNDEB) garantindo, desta maneira, recursos para ampliar a sua oferta.

\section{Educação de Jovens e Adultos}

A Educação de Jovens e Adultos surge no panorama educacional contemporâneo como uma modalidade de ensino de ampla importância, uma vez que representa uma excelente escolha para aqueles indivíduos que por diversos fatores foram excluídos da escola regular. As Diretrizes e Bases da Educação Nacional, Lei no 9394/94, em seu Art. $37^{\circ} \S 1^{\circ}$ preveem que a Educação de Jovens e Adultos se destine àqueles que não tiveram acesso (ou não deram continuidade) aos estudos no ensino fundamental e médio com oportunidades educacionais apropriadas. Assim, a EJA é vista como direito humano fundamental para a formação de jovens e adultos críticos e independentes preparados para enfrentar a realidade em que vivem.

Para a EJA, contemplar as necessidades e características dos sujeitos envolvidos neste processo é indispensável pensar a respeito da duração das horas-aulas, uma vez que para um individuo que está há certo tempo sem contato com a instituição há a probabilidade de ter um raciocínio mais lento e maior dificuldade de assimilação de conteúdos. Atendendo a essa consideração, o Parecer CNE/CNB 06/2010, Artigo 4, Inciso I orienta quanto à organização do ensino estabelecendo que para os anos iniciais do Ensino Fundamental, a duração da Educação de Jovens e Adultos deve ficar a critério dos sistemas de ensino; II - para os anos finais do Ensino Fundamental, a duração mínima deve ser de 1.600 (mil e seiscentas) horas; III - para o Ensino Médio, a duração mínima deve ser de 1.200 (mil e duzentas) horas, diferenciando-se, portanto, das orientações do ensino regular ${ }^{5}$.

A Educação de Jovens e Adultos tem como intenção primordial a reparação de uma dívida social; assim, ela torna-se um momento de nova significação de vida para os indivíduos que irão refletir acerca dos seus conhecimentos, e ampliá-los de forma a atender as suas necessidades pessoais. Também a ampliação de atendimento escolar, através dessa modalidade de educação, promove diferentes níveis de formação na 
medida em que passa a exercer funções mais específicas, atribuindo assim a essa modalidade de ensino três funções: a reparadora quando é oferecida uma escola de qualidade; função equalizadora quando permite ao indivíduo sua entrada no sistema educacional e função qualificadora quando propicia novos conhecimentos.

É essencial ratificar que a EJA é uma educação admissível capaz de mudar significativamente a vida de um indivíduo, permitindo uma nova história de vida e não pode ser apenas um momento a ser preenchido, mas um contínuo de significativo processo formativo. Di Pierro nos diz que:

\footnotetext{
Ao focalizar a escolaridade não realizada ou interrompida no passado, o paradigma compensatório acabou por enclausurar a escola para jovens e adultos nas rígidas referências curriculares, metodológicas, de tempo e espaço da escola de crianças e adolescentes, interpondo obstáculos à flexibilização da organização escolar necessária ao atendimento das especificidades desse grupo sociocultural. ${ }^{6}$
}

Desta forma é imprescindível o reconhecimento de que os alunos de EJA são indivíduos que possuem uma linguagem própria com experiências adquiridas, que vivem no mundo do trabalho com responsabilidades familiares e sociais e com conhecimentos construídos através de suas vivências as quais devem ser respeitados, pois as diferenças carregam uma riqueza de conhecimentos que devem ser contemplados pela instituição escolar. Arroyo acerca disso ressalta que:

\footnotetext{
Essas diferenças podem ser uma riqueza para o fazer educativo. Quando os interlocutores falam de coisas diferentes, o diálogo é possível. Quando só os mestres tem o que falar não passa de um monólogo. Os jovens e adultos carregam as condições de pensar sua educação como diálogo. Se toda educação exige uma deferência pelos interlocutores, mestres e alunos (as), quando esses interlocutores são jovens e adultos carregados de tensas vivências, essa deferência deverá ter um significado educativo especial. ${ }^{7}$
}

A particularidade da EJA se dá em função das experiências adquiridas pelos discentes ao longo de sua vida as quais devem ser contextualizadas em âmbito de sala de aula para que haja um sentido e um maior aprendizado. A Declaração de Hamburgo nos diz que: 
A educação de adultos engloba todo o processo de aprendizagem, formal ou informal, onde pessoas consideradas "adultas" pela sociedade desenvolvem suas habilidades, enriquecem seu conhecimento e aperfeiçoam suas qualificações técnicas e profissionais, direcionando-as para a satisfação de suas necessidades e as de sua sociedade $^{8}$

Assim, a Educação de Jovens e Adultos compreende não apenas as satisfações do processo escolar como também as necessidades dos indivíduos nela envolvidos. Dessa forma, para o acesso ao saber, a conscientização e a inserção do homem e da mulher na dinâmica e nos processos sociais, a Educação de Jovens e Adultos torna-se um requisito indispensável.

\section{Quem são os alunos da EJA}

A Educação de Jovens e Adultos contempla os indivíduos de uma camada da população, que traz consigo uma história de vida marcada por lutas, desafios, na qual o trabalho tem papel fundamental, uma vez que, por serem em sua maioria carentes, enxergam o trabalho como um aliado na melhoria de vida e por isso, são motivados a frequentar a instituição escolar em busca de novas oportunidades. São pessoas dotadas de conceitos culturais e valores éticos construídos a partir das experiências de vida que emergem do ambiente em que estão inseridos e que construíram uma concepção de mundo baseada em significados oriundos das suas vivências. Boa parte desses alunos se sente envergonhada de voltar à instituição escolar quando adultos, uma vez que possuem uma visão distorcida de que a escola é destinada a crianças o que cria uma certa resistência dessa parcela da população para frequentar a sala de aula.

De acordo com o Parecer do CNE/CEB 06/2010, obedecidos ao disposto no artigo 4º, incisos I e VII, da Lei no 9.394/96 (LDB) pode se matricular nesta modalidade de ensino jovens com idade mínima de 15 anos completos no ensino fundamental e 18 anos no ensino médio. ${ }^{9}$

Os discentes que frequentam essa modalidade de ensino enxergam esse momento como uma ruptura da exclusão e a sua identificação como ser humano e social, uma vez que, na nossa sociedade o valor que se dá ao conhecimento é muito grande. Segundo Britto, 
Um dos motivos que levam os trabalhadores adultos a ingressarem em programas de ampliação de escolaridade é a necessidade de ressocialização, [...] possibilidade de convivência saudável com outras pessoas de mesma condição e a realização de atividades proveitosas e gratificantes. ${ }^{10}$

É nessa perspectiva que os alunos de EJA frequentam a instituição escolar, e, mesmo eles estando cansados de um dia inteiro de trabalho, encontram motivação para ir assistir às aulas.

Faz-se necessário um pensar sobre esses indivíduos que possuem características específicas para se fazer uma educação que tenha sentido a fim de tornar o processo de ensino aprendizagem significativo, em que a sua trajetória de vida e as dificuldades de aprendizagem não possam interferir neste desenvolvimento. Sobre isso, Moraes nos diz que:

Tramado pelo processo de exclusão, oriundo da escola e da sociedade - com sua cultura própria e preconceitos dela decorrentes- o adulto que volta a estudar motivado por razões diversas, enfrenta uma gama de rótulos, que integram o seu auto conceito e acabam por diminuí-lo quanto às possibilidades que reconhecem em si próprios de realizarem aprendizagens escolares e de se perceberem como pessoas cognitivamente capazes de compreender questões mais complexas, de empreender, de criar, de confiar nas suas próprias percepções. Nesse sentido, podemos afirmar que a escola, ao receber esse aluno de volta, completa o seu trabalho de exclusão, uma vez que, pelo seu modo de atuação, 'comunica' ao sujeito a sua 'incapacidade', explicitada na incompreensão dos procedimentos e linguagem escolar, na dificuldade expressa que esse aluno apresenta de interagir com exercícios e raciocínios acadêmicos, distantes da sua realidade, desprovidos de uma 'ponte' que interligue a sabedoria do aluno com o saber da escola. Desse quadro resulta o 'consenso' que circula na escola de que o aluno da EJA é incapaz cognitivamente, tem grandes dificuldades de aprendizagem, problemas gravíssimos de memória, lentidão exagerada no raciocínio etc. ${ }^{11}$

É fundamental que o educador da Educação de Jovens e Adultos seja um indivíduo maleável, que ouça e conheça a realidade de seus alunos e propicie uma proposta pedagógica que respeite as especificidades, uma vez que, esses indivíduos são cercados de conhecimentos e um grande potencial de aprendizagem que precisa ser estimulado para 
que se reconheçam como capazes e tenham um melhor desenvolvimento no âmbito escolar.

É necessário que o professor desta modalidade de ensino esteja atualizado para que motive e aguce em seus alunos o desejo de adquirir novos conhecimentos. Os discentes que frequentam a EJA costumam ser indivíduos que fazem parte da camada social de baixa renda, que sobrevivem com o básico e obtém informações através da televisão que também é sua principal fonte de lazer.

O alunado desta modalidade de ensino possui em sua maioria um emprego de má qualificação com baixa remuneração e constantemente é visto como marginalizado diante da sociedade. Desta forma esses indivíduos objetivam retornar ao âmbito escolar para dar continuidade aos estudos na perspectiva da conquista de um trabalho mais significativo para que possa se realizar como cidadão, com um melhor poder aquisitivo, se reconhecer como ser social digno e capaz, na medida em que, por serem oriundos de um fracasso escolar se sentem desmotivados, com autoestima em baixa e se intitulam como incapazes buscando, assim, a instituição escolar para superarem esta carência.

Ao chegar no espaço escolar é evidente nestes jovens e adultos a sensação de vergonha, vergonha ao questionar ou responder questões, inquietação ao realizarem avaliações, o que acarreta uma maior dificuldade de aprendizagem. E sua sensação é mais aguçada quando o ambiente escolar o trata como um ser de raciocínio infantil ao ofertar salas infantilizadas, material didático igual ao utilizado pelo público infantil e com metodologia empregada na educação infantil. Negam aos discentes ferramentas direcionadas ao seu tempo real de vida. Gadotti ressalta que:

O aluno adulto não pode ser tratado como uma criança cuja história de vida apenas começa. Ele quer ver a aplicação imediata do que está aprendendo. Ao mesmo tempo, apresenta- se temeroso, sente-se ameaçado, precisa ser estimulado, criar auto-estima, pois a sua ignorância lhe traz tensão, angústia, complexo de inferioridade. Muitas vezes tem vergonha de falar de si, de sua moradia, de sua experiência frustrada da infância, principalmente com relação à escola. É preciso que 
tudo isso seja verbalizado e analisado. O primeiro direito do alfabetizando é o direito de se expressar. ${ }^{12}$

É necessário que a escola repense a sua ação educativa junto aos alunos adultos, tratando-os de forma a corresponder as suas reais expectativas.

\section{Significado}

Para uma contribuição expressiva do processo educativo se faz necessário uma compreensão dos significados que os discentes atribuem ao sistema escolar, uma vez que:

\footnotetext{
Significar alguém ou alguma coisa é assumir diante dessa pessoa ou objeto atitude de não-diferença, atribuindo-lhe determinado valor para a nossa existência. Quando assumimos, diante de qualquer que seja uma atitude de indiferença, isso significa que aquilo não tem para nós valor algum. Quando, contrário, significamos algo, essa significação poderá ser positiva (valor) ou negativa (contra-valor ou anti-valor). ${ }^{13}$
}

Desta maneira, a significação é imprescindível para uma ação efetiva, que tem um grande valor, por ser uma maneira de alcançar pontualmente os conhecimentos individuais dos discentes, bem como compreender o que eles objetivam no ambiente escolar para assim concretizar um processo de aprendizagem que faça sentido. Silva destaca que:

[...] É através dos significados contidos nos diferentes discursos, que o mundo social é representado e conhecido de certa forma, de uma bastante particular, é que o eu é produzido. E essa 'forma particular' é determinada precisamente por relação de poder [...] Os significados carregam a marca do poder que os produziu. ${ }^{14}$

O termo significado é definido por alguns autores como, uso, essência, sentido, sinônimo. E em uma conjuntura psicológica a palavra significado tem o seguinte conceito:

\footnotetext{
Significado não é o mesmo que sentido. Para ele o sentido é a soma dos eventos psicológicos que a palavra evoca na consciência. É um todo fluido e dinâmico, com zonas de estabilidade variável, da qual a mais aceitável, e precisa é o significado que é uma construção social de origem convencional (ou sócio - histórica) e de natureza relativamente estável. ${ }^{15}$
} 
Assim, a psicologia conclui que o significado é construído de acordo com as experiências de cada ser, experiências essas adquiridas através do cotidiano e cultura no qual estão inseridos. Trazendo essa definição para o contexto escolar, podemos concluir que, conhecendo os significados que os discentes atribuem à instituição escolar, poderemos propiciar um ambiente satisfatório as suas necessidades de acordo com a cultura e visão de mundo, principalmente na EJA cujos frequentadores já possuem uma longa trajetória de vida com experiências enriquecedoras que podem contribuir fortemente para um desejável processo de ensino-aprendizagem.

\section{Analisando os dados}

Objetivando responder a questão de pesquisa, optamos por entrevistar 5 alunos, sendo 2 do sexo masculino e 3 do sexo feminino, tendo em vista que a turma possui um total de 20 alunos matriculados, mas apenas 7 frequentam a escola regularmente. Para não expor os sujeitos pesquisados e garantir o sigilo das informações angariadas, eles foram representados pela sigla $\mathrm{A}$, acompanhado de número arábicos correspondente à quantidade de entrevistados. Como instrumentos de coleta de dados utilizamos a entrevista semiestruturada e o questionário aberto para obtermos informações mais amplas sobre o tema pesquisado.

\section{0 perfil dos entrevistados}

Os discentes entrevistados estão na faixa etária de 25 a 52 anos, e em sua maioria possuem o nível fundamental incompleto. Todos ficaram sem frequentar a escola por mais de cinco anos, possuem uma renda familiar inconstante, pois geralmente recebem proventos por semana, uma vez que nenhum dos indivíduos tem carteira de trabalho assinada. Trata-se de um público bem específico com realidades sociais e profissionais semelhantes.

\section{A ideia dos alunos acerca da escola que estudam}

Quando indagados os sujeitos sobre a instituição escolar e o que ela representa obtivemos as seguintes afirmativas: 
Ela para mim é tudo, pois aprendo muita coisa, aprendo a ler e contar. (A1)

Tudo, por que eu gosto de aprender a ler. (A2) Tudo de bom por que aprendo a escrever e ler. (A3)

A escola representa muito, ela é muito boa é nela que eu aprendo o que eu preciso para minha vida. (A4)

Tudo, a escola é tudo para mim, por que eu espero me formar e aprender a ler e escrever direito. (A5)

Diante destas afirmações, pode-se concluir que a escola tem papel fundamental na vida destes indivíduos, pois é por meio dela que objetivam aprender algo que há muito tempo foi difícil de alcançar. Ela é vista como o lugar propício e adequado para aprendizagem e desenvolvimento pessoal.

\section{Os motivos que levam os alunos a frequentar a escola}

Perguntados sobre os motivos que os levam a frequentar a escola obtivemos os seguintes depoimentos:

Venho para aprender e conversar com os colegas e com os professores aqui é bom e tranquilo. (A1)

Eu venho todo dia só falto quando estou doente, mesmo assim não gosto, eu me distraio e aprendo muito coisa e por isso não deixo de vim, quando penso em vim fico pensando nas coisas boas que aprendo aqui. (A2)

Não perco a escola por que aqui eu distraio a minha mente e esqueço os meus problemas é melhor do quer ficar em casa, e também quero ter mais conhecimentos. (A3)

Me motiva para ir porque quero ser alguém na vida, sem estudos não somos nada. (A4)

Em primeiro lugar para tirar a habilitação e também por que estudando a vida fica melhor, agente com o estudo arruma um trabalho bom e melhora a vida, minha vida a vida de minha mulher e também de minha filha. (A5)

Mediante esses relatos, percebe-se que a instituição escolar possui uma grande importância na vida destes discentes, uma vez que a relação adquirida contribui expressivamente para o desenvolvimento pessoal e intelectual deles. Além disso, a 
frequência à escola propicia um momento socializador que funciona, também, como um lazer para os alunos.

\title{
Quais fatores contribuíram para a volta dos discentes ao ambiente escolar
}

O retorno dos entrevistados à escola aponta para os seguintes depoimentos:

\author{
Voltei por que quero arrumar um emprego melhor e com o estudo tenho mais \\ chances. (A2) \\ Para arrumar um trabalho bom por que tenho esse objetivo. (A4) \\ Vim de novo para escola por que quero um bom emprego e só conseguimos um bom \\ emprego quando temos estudo. (A5)
}

Podemos identificar, nos depoimentos, a presença do fator trabalho como o grande responsável pela volta á escola, o ingresso no mercado encontra-se, pois, atrelado a uma qualificação que apenas , segundo os entrevistados, a escola pode propiciar.

\section{O que os discentes gostam no ambiente escolar}

Ao serem perguntados sobre o que eles gostavam no ambiente escolar os alunos foram bem amplos, disseram que gostam de tudo, principalmente dos professores, uma vez que eles são bem atenciosos, lhes proporcionam um ensino coerente com suas necessidades e objetivos. Na fala dos discentes ficou bem claro que a relação professor-aluno é bem harmoniosa e bem proveitosa, não há conflitos e sim uma amizade que ultrapassa o muro escolar, fato esse que contribui significativamente para o desenvolvimento do processo ensino- aprendizagem.

Para mim a escola seria melhor se tivesse aula de computação, a gente ia aprender mexer no computador, e arranjar um trabalho melhor. (A2)

A escola é boa, mas seria melhor com aula de computação, por que a escola tem computador, mas não dá aula para nos, e como quero outro trabalho só arrumo se souber usar o computador hoje o que mais exige é isso. (A4)

Hoje em dia todo trabalho precisa usar o computador, e como eu não tenho tempo durante o dia seria bom se na escola tivesse. (A5) 
Eu gosto de vim a escola, aqui eu aprendo posso arrumar um melhor trabalho e da um futuro aos meus filhos,eles e meu marido me dão apoio para vim mandando eu vim todo dia. (A2)

A escola é boa, eu aprendo e ensino a minha filha. (A4)

Minha mulher me incentiva a vim, eu venho com ela, mesmo estando cansado e nos aprendemos juntos para ensinar a nossa filha. (A5)

É possível identificar, nas falas, que a formação para o trabalho precisa estar coerente com as exigências do mundo moderno e, por isso, a necessidade de aulas de informática como fator essencial para uma melhor qualificação.

A preocupação com a família, tanto em relação à ajuda aos filhos assim como o apoio para a frequência à escola também favorecem o acesso e permanência dos alunos na escola, ratificando a importância do processo educativo na vida pessoal e profissional dos alunos.

\section{Considerações finais}

Neste momento de reflexão, retomamos o tema central colocado como objeto da pesquisa: qual o significado da escola para os alunos da Educação de Jovens e Adultos na Escola Municipal de Passagem Velha? Para obtermos respostas Levantamos questões como: Por que retornaram a escola? O que representa a escola para esses indivíduos? O que os motiva a frequentarem a instituição escolar? Diante destes questionamentos, pudemos tecer algumas considerações que trazem uma contribuição importante para a escola e para a Educação de Jovens e Adultos tendo em vista que apontam alguns aspectos que merecem ser considerados no processo educativo dessa modalidade de ensino.

A investigação demonstra que a escola para esses indivíduos tem um papel significativo em suas vidas, e que é através dela que terão uma melhoria de vida, tanto na questão profissional quanto pessoal. O aprendizado da leitura e escrita é primordial, porque acreditam que é por meio desta prática que terão um crescimento intelectual, bem como uma maior autonomia e aquisição dos seus direitos e maior participação na vida social e 
familiar. É evidente a satisfação dos alunos ao contribuírem no aprendizado dos filhos, podendo ensinar a eles as tarefas escolares, fato esse que sem retomar os estudos era impossível. A pesquisa retrata também que a estadia dos alunos em âmbito escolar eleva a autoestima, melhora o convívio social e favorece o ciclo de amizades. O papel do professor vai além de transmitir os conhecimentos escolares, e é visto como um amigo particular que os alunos podem procurar fora do ambiente escolar estabelecendo um vínculo de amizade muito gratificante.

Os jovens e adultos entrevistados demonstram que são motivados a frequentar a escola porque desejam uma melhoria de vida, querem ser exemplos de orgulho para os filhos e que a frequentam na perspectiva de um processo socializador que traz muito significado para sua vida pessoal. Um casal entrevistado nos chamou a atenção porque um motiva o outro a não faltar às aulas, pois têm um objetivo comum que é de oferecer à filha aquilo que não tiveram oportunidade de ter: uma educação de qualidade em tempo hábil para que ela possa concluir os estudos e alcançar um diploma de graduação.

Reconhecer esses indivíduos que frequentam essa modalidade de ensino bem como as suas necessidades contribui para um fazer pedagógico de qualidade, que faz sentido para os indivíduos, condizente com a sua realidade. E assim poder diminuir as taxas de evasão. O relato dos jovens e adultos entrevistados destaca a importância da sala de aula, que é um espaço não apenas de aquisição do conhecimento, mas também um espaço de troca de experiências, de aquisição de novas amizades que contribuem significativamente com suas vidas. Nela podem expressar seus desejos, seus objetivos, o que pensam e construir um futuro mais justo e mais humano para si mesmos e para sua família. Dentro desse processo, o trabalho do professor tem um significado fundamental para eles porque corresponde às suas expectativas de aquisição de conhecimentos e contribui também para a formação de laços de confiança e amizade.

Sentimo-nos bastante gratificados com o trabalho que desenvolvemos na medida em que pudemos identificar a importância que a escola exerce na vida dos entrevistados e como ela pode adequar-se para melhor atender às expectativas de uma clientela que necessita 
de uma base formativa, mais efetiva e mais eficaz, que responda a seus anseios profissionais e pessoais dentro da realidade em que vivem. Há que se repensar a escola e sua relação com o trabalho para que ela consiga exercer a sua função como agente de transformação e inserção social e contribua, assim, para a melhoria da qualidade de vida de seus alunos.

\section{Referências}

1. HADDAD, Sérgio; PIERRO, Maria Clara DI. Escolarização de Jovens e Adultos. Revista Brasileira de Educação, mai - ago. Número 014. São Paulo 2000.

2. FREIRE, Paulo. A importância do ato de ler: em três artigos que se completam. 39 ed. São Paulo: Cortez, 2000.

3. PAIVA, Vanilda Pereira. Educação popular e educação de adultos. 5 ed. São Paulo: Loyola, 1987.

4. BRASIL. Ministério da Educação. Disponível em:<http://portalmec.gov.br $>$ Data de acesso: 23 out. 2013.

5. BRASIL. Ministério da Educação. Lei de Diretrizes e Bases da Educação Nacional - LDB. Lei Darcy Ribeiro n 9.394/96. Brasília-1998.

6. DI PIERRO, Maria Clara. Notas sobre a definição da identidade e das políticas públicas de Educação de Jovens e Adultos no Brasil. Educação e Sociedade, Campinas, número especial, v.26, out. 2005

7. ARROYO, Miguel G. Educação de Jovens e Adultos - um campo de direitos e de responsabilidade pública in: SOARES, L. et ali (orgs.) Diálogos na Educação de Jovens e Adultos. Belo Horizonte: Autêntica, 200.

8. UNESCO, MEC. Declaração de Hamburgo sobre Educação de Adultos - V CONFINTEA. Brasília: MEC, 2004.

9. BRASIL. Sistema Brasil Alfabetizado. Disponível em: <http://brasilalfabetizado.fnde.gov.br> Data de acesso: 25 out. 2013.

10. BRITTO, Luiz Percival Leme. Contra o consenso: Cultura escrita, educação e participação. Campinas, SP: Mercado de Letras, 2003. 
11. MORAES, Márcia Amaral Corrêa de. Atuação psicopedagógica institucional na EJA: a prática da negociação nos processos de ensino e aprendizagem na escola. Ciências \& letras. Porto Alegre. N. 40, p. 147-160, dez, 2006.

12. GADOTTI, Moacir, RAMÃO, José. (Org.) Educação de Jovens e Adultos: teoria e prática e proposta. 3 ed. São Paulo: Cortez. 2001.

13. COSTA, Antonio Gomes da. O professor como educador: um resgate necessário e urgente. Salvador: Fundação Luís Eduardo Magalhães, 2001.

14. SILVA, Tomaz Tadeu da. Alienígenas na sala de aula. Petrópolis, RJ: Vozes, 1995. (Coleção estudos culturais em educação).

15. SIGARDO, A. Pino. O conceito de mediação semiótica em Vygotsky e seu papel na explicação do psiquismo humano. Caderno Cedes, ano XX (24): 38-50; 2000.

\section{Apêndice}

Questionário

PERFIL DOS EDUCANDOS DA EJA

1. Data de preenchimento do:

Município: Estado:

Nome da escola:

1.1. Nome:

1.2. Sexo: ( ) Feminino ( ) Masculino

1.3. Naturalidade:

1.4. Faixa etária:

( ) 18 a 20 anos ( ) 21 a 30 anos ( ) 31 a 40 anos ( ) 41 a 50 anos 60 anos ( ) acima de 60 anos

1.5. Estado civil: 
( ) solteiro/a ( ) casado/a ( ) separado/a ( ) viúvo/a

1.6. Você se considera:

( ) indígena ( ) pardo/a ( ) negro/a ( ) branco/a ( ) Amarelo/a

1.7. Quantidade de filhos:

( ) nenhum filho ( ) 1 filho ( ) 2 filhos ( ) 3 filhos ( ) 4 filhos ( ) 5 filhos mais de 5 filhos

2. Profissão:

3. Renda familiar:

( ) Até 1 salário mínimo ( ) 1 a 2 salários mínimos ( ) 2 a 3 salários ( ) 3 a 4 salários mínimos

4. Com quantos anos você começou a frequentar a escola?

5. Quantas vezes você repetiu o ano:

( ) nenhuma vez ( ) 1 vez ( ) 2 vezes ( ) 3 vezes ( ) mais de 3 vezes

6. Por que você parou de estudar?

7. Por que você voltou a estudar? Quais as suas motivações?

8. Para você, qual seria a escola ideal? 
9. Como você vê sua escola?

10. Qual o seu projeto para o futuro? 